\title{
Anxiety in multiple sclerosis is related to depressive symptoms and cognitive complaints
}

Citation for published version (APA):

Wallis, O., Bol, Y., Kohler, S., \& van Heugten, C. (2020). Anxiety in multiple sclerosis is related to depressive symptoms and cognitive complaints. Acta Neurologica Scandinavica, 141(3), 212-218. https://doi.org/10.1111/ane.13191

Document status and date:

Published: 01/03/2020

DOI:

10.1111/ane.13191

Document Version:

Publisher's PDF, also known as Version of record

Document license:

Taverne

Please check the document version of this publication:

- A submitted manuscript is the version of the article upon submission and before peer-review. There can be important differences between the submitted version and the official published version of record.

People interested in the research are advised to contact the author for the final version of the publication, or visit the DOI to the publisher's website.

- The final author version and the galley proof are versions of the publication after peer review.

- The final published version features the final layout of the paper including the volume, issue and page numbers.

Link to publication

\footnotetext{
General rights rights.

- You may freely distribute the URL identifying the publication in the public portal. please follow below link for the End User Agreement:

www.umlib.nl/taverne-license

Take down policy

If you believe that this document breaches copyright please contact us at:

repository@maastrichtuniversity.nl

providing details and we will investigate your claim.
}

Copyright and moral rights for the publications made accessible in the public portal are retained by the authors and/or other copyright owners and it is a condition of accessing publications that users recognise and abide by the legal requirements associated with these

- Users may download and print one copy of any publication from the public portal for the purpose of private study or research.

- You may not further distribute the material or use it for any profit-making activity or commercial gain

If the publication is distributed under the terms of Article $25 \mathrm{fa}$ of the Dutch Copyright Act, indicated by the "Taverne" license above, 


\title{
Anxiety in multiple sclerosis is related to depressive symptoms and cognitive complaints
}

\author{
Olga Wallis ${ }^{1}$ (D) | Yvonne Bol ${ }^{2}$ | Sebastian Köhler ${ }^{3}$ | Caroline van Heugten ${ }^{3,4,5}$
}

\author{
${ }^{1}$ Department of Medical Psychology, ETZ \\ Hospital, Tilburg, The Netherlands \\ ${ }^{2}$ Department of Clinical and Medical \\ Psychology, Zuyderland Medical Center, \\ Sittard-Geleen, The Netherlands \\ ${ }^{3}$ School for Mental Health and \\ Neuroscience, Maastricht University \\ Medical Center, Maastricht, The \\ Netherlands \\ ${ }^{4}$ Department of Neuropsychology and \\ Psychopharmacology, Maastricht University, \\ Maastricht, The Netherlands \\ ${ }^{5}$ Brain Injury Center Limburg, Maastricht, \\ The Netherlands \\ Correspondence \\ Yvonne Bol, Dr. H. van der Hoffplein 1, 6162 \\ BG Sittard-Geleen, The Netherlands. \\ Email:y.bol@zuyderland.nl
}

Objectives: Multiple sclerosis (MS) patients suffer from high levels of anxiety. However, it is unclear which factors are related to anxiety, since study results are inconsistent, and the associated factors have not been examined comprehensively. In this study, we investigated the demographic, disease-related and psychological factors associated with anxiety in MS patients.

Materials and methods: Cross-sectional data of 119 MS patients were used. Anxiety and depressive symptoms (Hospital Anxiety and Depression Scale), fatigue (Fatigue Severity Scale), cognitive complaints (Cognitive Failures Questionnaire) and cognitive functioning (Wisconsin Card Sorting Test, Controlled Oral Word Association Test, Letter Digit Substitution Test, Concept Shifting Test, Wechsler Memory Test Faces and the Dutch version of the California Verbal Learning Test) were measured. Bivariate and multivariable regression analyses were conducted to test the associations between anxiety and potential contributing factors.

Results: In this sample, $42 \%$ of the MS patients had clinically significant levels of anxiety, defined by a score $\geq 8$ on the anxiety subscale of the Hospital Anxiety and Depression Scale (HADS). A significant correlation was found between anxiety and depressive symptoms, fatigue, cognitive complaints and psychiatric history. In the multivariable analysis, only depressive symptoms and cognitive complaints remained significantly related to anxiety.

Conclusions: Anxiety is common in MS patients and most strongly related to psychological factors. This knowledge can be taken into account when treating patients with MS. Further research is needed using longitudinal designs and incorporating other factors known to influence anxiety, such as coping, negative affectivity and social support.

\section{KEYWORDS}

anxiety, cognition, contribute, depression, multiple sclerosis, psychological

\section{1 | INTRODUCTION}

Multiple sclerosis (MS) is a chronic and incurable disease of the central nervous system. It is the most common neurological disorder in young adults with an unpredictable and often degenerative course. ${ }^{1} \mathrm{MS}$ can affect both physical and emotional functioning and has a negative influence on quality of life (QoL). ${ }^{2}$ Symptoms such as fatigue, depression, anxiety and cognitive impairment have been found to be more important predictors of QoL in MS patients than physical symptoms and neurological impairment. ${ }^{3-5}$

In line with others afflicted by chronic autoimmune diseases characterized by exacerbations, such as inflammatory bowel 
disease ${ }^{6}$ and rheumatoid arthritis, ${ }^{7} \mathrm{MS}$ patients suffer from high levels of anxiety. The lifetime prevalence of anxiety disorders ranges from $20 \%$ to $45 \%$ throughout the course of $\mathrm{MS}^{8}$ and exceeds the lifetime prevalence of anxiety disorders in healthy people (ie 13\%). ${ }^{9}$ Heterogeneity in estimates of the prevalence of anxiety is probably due to differences in the operationalization of anxiety, measurement instruments and study design.

Several studies have shown that clinically significant anxiety symptoms in MS are about as frequent as depressive symptoms ${ }^{5,10}$ or even higher ${ }^{11}$ and that they often co-occur. ${ }^{8}$ A systematic review confirmed that psychiatric comorbidity in MS, particularly depression and anxiety, is common. However, anxiety is relatively under-researched, with nearly twice as many studies focusing on depression in MS in comparison with anxiety. ${ }^{5}$ Anxiety itself can aggravate symptoms such as fatigue and cognitive complaints and can have a negative influence on work, family and social life. ${ }^{12}$ Therefore, it is important to know which associations with anxiety can be identified in order to improve screening and treatment of anxiety in the MS population.

Researchers have investigated several predictors of anxiety in MS, but results are mixed, and the determinants generally have been studied separately. Demographic factors do not seem to be related to anxiety in MS, although gender has been found to have an influence sporadically. ${ }^{13-16}$ While the prevalence of anxiety tends to decline with age in the general population, ${ }^{17}$ age does not seem to be a prominent factor for anxiety in MS. ${ }^{15,16}$ Employment status shows contradictory associations with anxiety. Participants who were employed at baseline measurement reported more anxiety after 4 months. ${ }^{16}$ In contrast, cross-sectionally, higher anxiety scores were significantly associated with not being employed. ${ }^{18}$

The association between disease-related factors and anxiety shows mixed results across studies. Having more disabilities and not being on immunotherapy is associated with higher levels of anxiety. ${ }^{13,15,18}$ However, relapsing-remitting MS (RRMS) is associated with more anxiety in comparison with primary progressive (PPMS) and secondary progressive (SPMS) forms of MS. ${ }^{19}$ This seems counterintuitive, since RRMS patients have generally lower neurological disability and are more likely to receive immunotherapy. Other studies have failed to establish a correlation between anxiety and disabilities, the presence of an exacerbation, disease duration, MS type and immunotherapy. ${ }^{16,20}$

Cognitive disorders are present in $43 \%-70 \%$ of MS patients ${ }^{4}$ and have been related to anxiety. Specifically, a decrease in information-processing speed and problems in executive functions have been associated with increased anxiety. ${ }^{21,22}$ Yet, other studies have not found a correlation with general cognitive functioning, memory, attention and executive functioning. ${ }^{20,23,24}$ Finally, anxiety is related to subjective cognitive complaints, rather than with objective neuropsychological measurements. ${ }^{25}$

Studies on anxiety and depression in MS have generally found significant correlations between the two. ${ }^{13-16,23}$ Higher levels of disability and general stress are associated with being anxious, with mood playing an important mediating role in this relation. ${ }^{13}$ This is in line with a prospective study, in which anxiety, depression and fatigue at baseline were better predictors of anxiety course over 2 years than any factors related to disease, demographics, cognitive ability, current stressors, psychosocial attributes or lifestyle. ${ }^{15}$ Other studies have found correlations between fatigue and anxiety. ${ }^{20}$ Earlier psychiatric diagnosis precedes anxiety disorders in $34 \%$ of MS patients. ${ }^{11}$

In sum, studies on anxiety in MS have shown mixed findings to date, and the underlying factors have rarely been studied in relation to each other. Results regarding the factors that contribute to anxiety in MS are contradictory for demographic, disease-related, cognitive and psychological variables. This fact was also underlined in a review by Butler et al. ${ }^{3}$ Moreover, in this study most factors were studied separately, while the associations between these factors and anxiety are of great interest for clinical practice. To our knowledge, only the one study ${ }^{20}$ used a multivariable model, in which demographic, disease-related, cognitive (although only tested by one test) and psychological variables were studied comprehensively. Only fatigue, pain and lower age at onset were significantly associated with anxiety. ${ }^{20}$ More studies are needed to examine the independent determinants of anxiety in MS.

Multiple sclerosis patients experience high levels of anxiety which are important predictors of lower QOL, but factors related to anxiety are not straightforward. Directions for treatment remain to be discovered. Therefore, the overall aim of this study was to explore a broad spectrum of potential factors that contribute to anxiety in MS patients. We focused on the following questions: To what extent do MS patients experience anxiety symptoms? And which demographic, disease-related, cognitive and psychological factors are most strongly related to anxiety in MS patients?

\section{2 | METHODS}

\section{1 | Participants and procedure}

This study was a retrospective, cross-sectional, clinical cohort study. The records of 122 patients with a definite clinical diagnosis of MS by the McDonald criteria ${ }^{26}$ were retrieved from the Academic MS Centre of Zuyderland Medical Centre in Sittard-Geleen, the Netherlands. The medical records of routine follow-up visits were used (March 2009 to October 2014), including a standardized neuropsychological evaluation. Exclusion criteria were the presence of other comorbid neurological impairments, age below 18 or above 65 and insufficient Dutch language proficiency.

The measurements were part of a routine clinical assessment. All the patients were informed that their files could be used retrospectively and anonymously for research purposes, unless they objected. At the time of the data collection, this approval was sufficient in terms of medical ethics. The study was conducted according to the Declaration of Helsinki. 


\section{2 | Measures}

Demographic (gender, age, social status, employment status, years of education and psychiatric history) and disease-related factors (time since diagnosis, type of MS, neurological disability, comorbid disease and medication) were retrieved from the patients' files. Neurological disability was measured with the Expanded Disability Status Scale (EDSS) ${ }^{27}$ administered recently ( $<3$ months) by an experienced neurologist. This scale comprises the evaluation of eight functioning systems (pyramidal, cerebellar, brainstem, mental, bowel and bladder, visual-optic, sensory and other). The EDSS score ranges from 0 to 10, where 0 indicates a normal neurological examination, and 10 indicates death due to MS.

To measure anxiety and depression, the Hospital Anxiety Depression Scale subscales for anxiety (HADS-A) and depression (HADS-D) were used. ${ }^{28}$ Both subscales consist of seven items, rated on a 4-point verbal rating scale, with higher scores indicating higher levels of anxiety or depressive symptoms. Total scores range from 0 to 21 . A score of 8 or higher per subscale indicates a probable depression or generalized anxiety disorder in $\mathrm{MS}^{29}$

The Fatigue Severity Scale (FSS) was used to measure severity and the impact of physical fatigue. ${ }^{30}$ The scale consists of nine items, assessed on a 7-point Likert scale. The overall score is based on the average of all items and can range between 1 and 7, where scores of 4 or higher indicate severe fatigue. ${ }^{31}$ The FSS has been found to be a reliable and valid measure of fatigue in MS patients. ${ }^{32}$

The Cognitive Failure Questionnaire (CFQ) measures self-reported failures in perception, memory and motor function. In 25 questions, the respondent is asked to indicate the frequency with which he or she makes mistakes on a five-point scale. The total score can vary from 0 to 100; higher scores implicate more reported cognitive mistakes. ${ }^{33}$ Scores above two SD of average are seen as significantly high; cut-off $\geq 55 .^{34}$ Internal consistency of the CFQ in MS patients is high (Cronbach's $=0.92) .{ }^{35}$

\section{3 | Neuropsychological tests}

The Dutch guidelines for MS treatment recommend that a test be conducted on the five domains most affected in MS: informationprocessing speed, learning and memory, executive functioning, fluency and visuospatial functioning. ${ }^{36}$ Our study used four of these five domains because of insufficient data about visuospatial functioning. All the tests were sensitive, and the measures were valid in MS patients. $4,37,38$

We used the oral version of the Letter Digit Substitution Test (LDST) to measure information-processing speed. ${ }^{4}$ The LDST is comparable to the Symbol Digit Memory Task (SDMT) and is widely used in the Netherlands, also among MS patients. ${ }^{35}$

To measure executive functioning, we administered the Concept Shifting Test (CST) and the Wisconsin Card Sorting Test (WCST). We used the total completion score of part B (letters) and part C (letters and digits) and the interference score of the CST to measure divided attention and shifting. ${ }^{38}$ We used the WCST number of responses, total categories completed and total errors and trials needed to complete the first category to measure abstract reasoning and problem solving. ${ }^{39}$

We used two verbal fluency tasks: the Groninger Intelligence Test (GIT) semantic fluency task ${ }^{40}$ and the Controlled Oral Word Association Test (COWAT) phonological fluency. ${ }^{41}$ Concerning semantic fluency, we used the total number of animals and occupation, phonological fluency and the total score of words with the first letters $\mathrm{D}, \mathrm{A}$ and $\mathrm{T} .{ }^{40,41}$

Domain learning and memory were measured with the Dutch version of the California Verbal Learning Test-II (CVLT-II) ${ }^{42}$ and the Wechsler Memory Test (WMT) Faces. ${ }^{43} \mathrm{MS}$ patients often have difficulty recalling words from long-term memory. ${ }^{4}$ We used the VGLT total score and the WMT faces recognition 1 and 2 .

\subsection{Statistical analyses}

The association between anxiety symptoms and the demographic (gender age, education years, social status, work status, psychiatric history), disease-related (time since diagnosis, type MS, EDSS, comorbid disease, immunotherapy status, cognitive tests) and psychological variables (depressive symptoms, fatigue, cognitive complaints) was tested one by one in one-way ANOVAs. Variables that were statistically significant at $P<.05$ were entered in a multivariable linear regression analysis with backward selection of independent variables. Multicollinearity was inspected using the variance inflation factor (VIF), with a VIF > 3.0 indicating possible multicollinearity. The standardized regression coefficients $\beta$ were used to compare the relative correlation between predictor and anxiety outcome. For cognition, factor analysis was conducted prior to the main analyses to reduce the number of cognitive test variables. In all analyses, a Pvalue of $<.05$ for two-sided tests was considered statistically significant. Analyses were done in Stata 15.1 and SPSS version 24 (IBM).

\section{3 | RESULTS}

\section{1 | Participants}

From the 122 MS patients, HADS data were missing for two patients and information about MS type for one patient, resulting in a final sample of 119 MS patients for analysis. Table 1 presents their demographic and disease-related factors.

\section{2 | Anxiety, depression, fatigue and cognitive functioning}

Table 2 presents the means and standard deviations of anxiety, depression, fatigue and cognitive complaints. The mean anxiety score was 7.7 (SD 4.1). Of the $119 \mathrm{MS}$ patients, $42.0 \%$ had an anxiety score 
TABLE 1 Patients characteristics

\begin{tabular}{|c|c|c|c|}
\hline $\begin{array}{l}\text { Patients characteristics } \\
(\mathrm{N}=119)\end{array}$ & Number & Mean & SD \\
\hline \multicolumn{4}{|l|}{ Demographic factors } \\
\hline $\operatorname{Sex}(f / m)$ & $75 / 44$ & & \\
\hline Age & & 47.8 & 9.4 \\
\hline Education years & & 13.4 & 3.6 \\
\hline $\begin{array}{l}\text { Social status (relation/no } \\
\text { relation) }\end{array}$ & $100 / 19$ & & \\
\hline $\begin{array}{l}\text { Work status (working/ } \\
\text { non-working) }\end{array}$ & $32 / 87$ & & \\
\hline Psychiatric history (y/n) & $27 / 92$ & & \\
\hline \multicolumn{4}{|l|}{ Disease-related factors } \\
\hline Time since diagnosis in years & & 7.4 & 8.2 \\
\hline $\begin{array}{l}\text { Type MS (RRMS/PPMS/ } \\
\text { SPMS) }\end{array}$ & $79 / 20 / 20$ & & \\
\hline EDSS & & 3.5 & 1.6 \\
\hline Comorbid disease $(y / n)$ & $27 / 92$ & & \\
\hline Medication MS (y/n) & $84 / 35$ & & \\
\hline
\end{tabular}

Note: Social status consist of: (a) relation: married, living together or LAT (Living Apart Together), (b) no relation: single/divorced/widow(er). Employment status consist of: (a) employed: working fulltime, part-time, volunteer work or therapeutic, (b) not employed: no work or WAO (law of incapacity of work) or VUT (early retirement).

Abbreviations: EDSS, Expanded Disability Status Scale; PPMS, primary progressive MS; RRMS, relapsing-remitting MS; SPMS, secondary progressive MS

above cut-off (HADS A $\geq 8$ ). On the depression scale, 37.8\% scored above the cut-off. The sample shows a high percentage of fatigue, with $88.2 \%$ scoring above the cut-off.

\section{3 | Neuropsychological tests}

Factor analysis suggested a model with four factors had a good fit $($ RMSEA $=0.058, \mathrm{CFI}=0.975$ and $\mathrm{TLI}=0.965$; see Appendix S1). We labelled the factors: Factor 1: Abstract Reasoning and Flexibility; Factor 2: Verbal Fluency; Factor 3: Attention and Processing Speed; Factor 4: Memory.

\subsection{Bivariate analyses}

All demographic and disease-related factors, neuropsychological factors and psychological factors were separately associated with the anxiety score. Bivariate analysis showed there was a significant association with depression score, cognitive complaints and fatigue. None of the neuropsychological factors showed significant correlations with anxiety. Of the other variables, only psychiatric history showed a significant association. Patients without a psychiatric history had a mean score on the HADS-A of 7.1, while patients with a psychiatric history had a mean score of 9.4. The results are presented in Table 3.
TABLE 2 Means and standard deviations of psychological questionnaires and neuropsychological tests

\begin{tabular}{|lrrr|}
\hline Questionnaire/Test & Mean & \multicolumn{1}{l}{ SD } & \% above cut-off \\
\hline Psychological questionnaires & & & \\
\hline HADS-A & 7.7 & 4.1 & 42.0 \\
\hline HADS-D & 6.5 & 4.0 & 37.8 \\
\hline FSS & 48.9 & 10.3 & 88.2 \\
\hline CFQ & 47.9 & 14.6 & 31.9 \\
\hline Neuropsychological tests & & & \\
\hline WISC number of responses & 63.0 & 15.0 & \\
\hline WISC number of categories & 5.0 & 1.7 & \\
\hline completed & & & \\
\hline WISC number of mistakes & 29.3 & 21.2 & \\
\hline WISC number of trials to & 21.9 & 25.4 & \\
\hline complete first category & & & \\
\hline Fluency animals & 20.7 & 5.8 & \\
\hline Fluency occupation & 15.6 & 5.1 & \\
\hline COWAT total & 32.6 & 11.8 & \\
\hline LDST read & 34.8 & 8.8 & \\
\hline CST b & 21.2 & 11.7 & \\
\hline CST c & 30.9 & 21.3 & \\
\hline WMT faces recognition 1 & 34.3 & 4.7 & \\
\hline WMT faces recognition 2 & 35.5 & 4.9 & \\
\hline VLGT total score & 51.9 & 11.9 & \\
\hline & & & \\
\hline
\end{tabular}

Abbreviations: CFQ, Cognitive Failure Questionnaire; COWAT, Controlled Oral Word Association Test; CST, Concept Shifting Test; FSS, Fatigue Severity Scale; HADS, Hospital Anxiety and Depression Scale; LDST, Letter Digit Substitution Test; VLGT, Dutch version of California Verbal Learning Test; WCST, Wisconsin Card Sorting Test; WMT, Wechsler Memory Test.

\section{5 | Multivariable analysis}

Multivariable backward linear regression analysis was conducted with the variables with a significant association with anxiety from the above model step. After this analysis, only the depression score (HADS-D) and cognitive complaints (CFQ) remained significantly related to anxiety (Table 4). Higher scores for both were associated with more anxiety symptoms.

\section{4 | DISCUSSION}

In this cross-sectional study, we investigated the prevalence of anxiety in a clinical cohort of MS patients and potential contributing factors. We found that almost half of the patients (42\%) had clinically significant anxiety symptoms. This percentage was even higher than those with depressive symptoms (37.8\%). From all the factors investigated, psychiatric history, depressive symptoms, fatigue and cognitive complaints contributed to anxiety scores, if studied in isolation, but only depressive symptoms and cognitive complaints remained significant in the multivariable analysis. 
TABLE 3 Results bivariate analysis testing the association with anxiety

\begin{tabular}{|c|c|c|c|}
\hline & $B$ & $\begin{array}{l}\text { Confidence } \\
\text { interval (95\%) }\end{array}$ & $P$-value \\
\hline \multicolumn{4}{|l|}{ Demographic variables } \\
\hline Gender (male) & -0.73 & -2.27 to 0.82 & .36 \\
\hline Age & -0.02 & -0.10 to 0.60 & .63 \\
\hline Education in years & -0.17 & -0.47 to 0.12 & .24 \\
\hline $\begin{array}{l}\text { Social status (no } \\
\text { relation) }\end{array}$ & -1.01 & -3.05 to 1.03 & .33 \\
\hline $\begin{array}{l}\text { Employment status } \\
\text { (not employed) }\end{array}$ & 0.57 & -1.11 to 2.26 & .50 \\
\hline $\begin{array}{l}\text { Psychiatric history } \\
\text { (none) }\end{array}$ & -2.33 & -4.07 to -0.60 & $.01^{*}$ \\
\hline \multicolumn{4}{|l|}{ Disease-related variables } \\
\hline $\begin{array}{l}\text { Time since diagnosis } \\
\text { in years }\end{array}$ & -0.01 & -0.10 to 0.08 & .84 \\
\hline Type MS (RRMS) & -0.13 & -1.72 to 1.46 & .87 \\
\hline EDSS & -0.26 & -0.73 to 0.21 & .27 \\
\hline $\begin{array}{l}\text { Comorbid disease } \\
\text { (none) }\end{array}$ & -1.19 & -2.96 to 0.59 & .19 \\
\hline $\begin{array}{l}\text { Medication MS } \\
\text { (none) }\end{array}$ & -0.14 & -1.78 to 1.51 & .87 \\
\hline \multicolumn{4}{|l|}{ Psychological variables } \\
\hline HADS D & 0.58 & $0.43-0.74$ & $.00^{*}$ \\
\hline FSS & 0.09 & $0.02-0.16$ & $.01^{*}$ \\
\hline CFQ & 0.15 & $0.11-0.20$ & $.00^{*}$ \\
\hline \multicolumn{4}{|l|}{ Cognitive variables } \\
\hline $\begin{array}{l}\text { Factor } 1 \text { Abstract } \\
\text { reasoning and } \\
\text { flexibility }\end{array}$ & -0.04 & -0.11 to 0.04 & .31 \\
\hline $\begin{array}{l}\text { Factor } 2 \text { Verbal } \\
\text { fluency }\end{array}$ & 0.00 & -0.21 to 0.21 & .99 \\
\hline $\begin{array}{l}\text { Factor } 3 \text { Attention } \\
\text { and processing } \\
\text { speed }\end{array}$ & 0.00 & -0.12 to 0.12 & .97 \\
\hline Factor 4 Memory & 0.22 & -0.16 to 0.61 & .26 \\
\hline
\end{tabular}

Abbreviations: CFQ, Cognitive Failure Questionnaire; EDSS, Expanded Disability Status Scale; FSS, Fatigue Severity Scale; HADS-D, Subscale depression of the Hospital Anxiety and Depression Scale.

${ }^{*}$ Significant $P<.05$.

Anxiety prevalence is higher in our sample than has been reported before, with a recent review showing a pooled prevalence of $34 \% .{ }^{10}$ However, when anxiety was defined by a HADS-A score $\geq 8$ in that review, the prevalence was similar to ours (46.2\%). An interpretation of the prevalence rates, therefore, needs to be done with caution, since it depends on the measure used.

Depressive symptoms and cognitive complaints were strongly related to anxiety. The correlation between anxiety and depression has been demonstrated ${ }^{13,14,16,23}$ and can been explained by a shared underlying aetiology, for which psychological and biological pathways have been suggested. In the model of Watson et al, ${ }^{44}$ symptoms and
TABLE 4 Results multivariate regression analysis

\begin{tabular}{lllll} 
Variables & $\boldsymbol{\beta}$ & Standard error & \multicolumn{1}{l}{$\boldsymbol{t}$} & $\boldsymbol{P}$-value \\
\hline Psychiatric history & -.23 & 0.72 & -0.31 & .75 \\
\hline HADS D & .42 & 0.08 & 5.20 & $.00^{*}$ \\
\hline FSS & .02 & 0.03 & 0.69 & .49 \\
\hline CFQ & .09 & 0.02 & 3.80 & $.00^{*}$ \\
\hline
\end{tabular}

Abbreviations: CFQ, Cognitive Failure Questionnaire; FSS, Fatigue Severity Scale; HADS-D, subscale Depression of the Hospital Anxiety and Depression Scale.

*Significant $P<.05$.

diagnosis of anxiety and depression are considered to depend on similar factors, particularly negative affectivity, a broad and pervasive predisposition to experience negative emotions that influences someone's cognition, self-concept and world view. ${ }^{45}$ This subjective distress factor consistently correlates with anxiety and depressive symptoms. ${ }^{44}$ Also, cognitive complaints are related to negative affectivity. ${ }^{46}$ Since in our study both depressive symptoms and cognitive complaints are related to anxiety, negative affectivity might be of crucial importance in the risk of developing psychopathologies in the MS population. A biological hypothesis for the overlap between anxiety and depression is that both can be the outcome of the same biological substrate, such as immune system dysregulation measured, for example, by increased levels of cytokines. ${ }^{47}$

The significant relation between cognitive complaints and anxiety in MS patients is also in line with earlier findings and might be part of the above relation between anxiety and depression. Anxiety, along with depression and mental fatigue, accounts for a substantial part of the total variance of cognitive complaints in MS patients. ${ }^{25,35}$ Moreover, in a longitudinal study, ${ }^{48}$ the authors showed that anxiety and fatigue were significant predictors of general cognitive concerns during a 2-year follow-up. ${ }^{48}$ However, whether cognitive complaints contribute to anxiety or the other way around cannot be answered on the basis of our cross-sectional data.

None of the demographic and disease-related factors were associated with anxiety in our multivariable analyses. In earlier research, results on different demographic and disease-related factors were contradictory, which is most probably the result of heterogeneity between studies in terms of samples and methods, and a failure to account for other related factors. ${ }^{11,16,18,20}$

We did not find gender or employment status to be associated with anxiety. Gender effects might only be found in the prediagnostic phase ${ }^{14}$ and in patients with low disabilities (EDSS < 6.5). ${ }^{13}$ Concerning employment status, our sample was less employed $(27 \%$ employed), in contrast with other studies, where $66 \%$ and $61 \%$, respectively, were employed. This difference can be explained by a broader recruitment of MS patients in other samples. ${ }^{16,18}$ In our sample of patients, in which all of them were following rehabilitation or psychological programs and tended to be less employed, we did not find an association with anxiety.

In earlier studies that did find an effect with EDSS, patients were less disabled and recently diagnosed. ${ }^{13,18}$ The relation between 
disabilities and anxiety might only be present in MS patients with relatively few disabilities, as for gender effects.

In our data, we found no relation between cognitive functioning and anxiety in the final analyses. Correlations in other studies might be explained by the use of the State-Trait Anxiety Inventory (STAI) instead of the HADS ${ }^{21}$ and the use of other neuropsychological tests, ${ }^{21,22}$ or, again, failure to account for other contributors in a single model.

The importance of psychological factors has been stated in earlier research on quality of life in MS patients, which demonstrates that fatigue, depression, anxiety and cognitive impairment are more important contributors of quality of life than physical symptoms and neurological impairment. ${ }^{3-5}$ Our study confirms this pattern and is the first MS study on anxiety that includes demographic, disease-related and psychological variables in a multivariable analysis, including comprehensive cognitive functioning. We suggest it is not the disease-specific factors that contribute to anxiety, but how well patients adjust to the disease. The importance of coping in quality of life and in anxiety is stated in multiple MS studies. ${ }^{18,24,49}$ More specifically, a greater reliance on emotion-focused coping strategies is related to poor psychosocial adjustment, depression and anxiety. ${ }^{49}$ Lack of correlations between these disease-related variables, together with the strong relation between anxiety, depression and cognitive complaints, can possibly be explained by coping as a moderating variable.

Our study is one of the first to investigate multiple factors associated to anxiety in MS. Since the prevalence of anxiety is high and it is a strong predictor of lower QOL in MS, it is important to learn more about factors which contribute to anxiety and may be modifiable. Recently, it was found that modifiable lifestyle factors, such as food, smoking, alcohol and physical activity, were associated with depression but not with anxiety. ${ }^{50}$ This is not surprising given the importance of psychological factors. Further research into potential alleviating factors and possible treatments is therefore necessary. A recent meta-analysis showed that cognitive behavioural therapy and mindfulness-based therapies are successful in reducing psychological distress in patients with MS, but effects are small to moderate; more high-quality treatment studies are warranted. ${ }^{51}$

Some limitations of our study need to be mentioned. First, our study has a cross-sectional design, so we cannot draw conclusions about the direction of the effects. Level of anxiety can also be a predictor of depressive symptoms or cognitive complaints, as stated earlier. Also, we did not include the amount of social support, which has been shown to be a protective factor for anxiety. ${ }^{11}$ We also did not include other psychological factors, such as coping or negative affectivity. Finally, we did not use the core battery of the Minimal Assessment of Cognitive Function in MS (MACFIMS), ${ }^{37}$ since we missed visuospatial attention. Little is known about this cognitive domain and its relationship with anxiety. Only one study on this topic ${ }^{52}$ showed visuospatial attention not to be correlated with anxiety.

In conclusion, anxiety is common in MS patients and most strongly relates to psychological factors rather than demographic or disease-related factors. Future research on anxiety in MS should focus on additional psychological factors, such as negative affectivity, coping and social support. Furthermore, longitudinal research is needed to investigate the predictive factors of anxiety. Since suicidal risk and mortality is elevated in MS patients with psychiatric comorbidity, including anxiety, ${ }^{11}$ clinicians should pay specific attention to patients with anxiety. Our results point towards the potential effectiveness of psychological treatment. Early recognition of anxiety after diagnosis of MS is important to offer psychological treatment and improve the quality of life of MS patients.

\section{ACKNOWLEDGMENTS}

The authors would like to thank all the study participants and Jolanda de Vries for her helpful comments on the manuscript and Evelien Bergsma for adjusting the manuscript on style.

\section{CONFLICT OF INTEREST}

The authors have no competing interests to report.

\section{ORCID}

Olga Wallis iD https://orcid.org/0000-0001-9915-7881

\section{DATA AVAILABILITY STATEMENT}

The data that support the findings of this study are available on request from the corresponding author. The data are not publicly available due to privacy or ethical restrictions.

\section{REFERENCES}

1. Compston A, Coles A. Multiple sclerosis. Lancet. 2008;372(9648):1502-1517.

2. Mitchell AJ, Benito-León J, González JM, Rivera-Navarro J. Quality of life and its assessment in multiple sclerosis: integrating physical and psychological components of wellbeing. Lancet Neurol. 2005;4(9):556-566.

3. Butler E, Matcham F, Chalder T. A systematic review of anxiety amongst people with multiple sclerosis. Mult Scler Relat Disord. 2016:10:145-168.

4. Chiaravalloti ND, DeLuca J. Cognitive impairment in multiple sclerosis. Lancet Neurol. 2008;7(12):1139-1151.

5. Marrie RA, Reingold S, Cohen J, et al. The incidence and prevalence of psychiatric disorders in multiple sclerosis: a systematic review. Mult Scler J. 2015;21(3):305-317.

6. Neuendorf R, Harding A, Stello N, Hanes D, Wahbeh H. Depression and anxiety in patients with inflammatory bowel disease: a systematic review. J Psychosom Res. 2016;87:70-80.

7. Fiest KM, Hitchon CA, Bernstein $\mathrm{CN}$, et al. Systematic review and meta-analysis of interventions for depression and anxiety in persons with rheumatoid arthritis. J Clin Rheumatol. 2017;23(8):425.

8. Wood B, Van Der Mei IA, Ponsonby AL, et al. Prevalence and concurrence of anxiety, depression and fatigue over time in multiple sclerosis. Mult Scler J. 2013;19(2):217-224.

9. Steel Z, Marnane C, Iranpour C, et al. The global prevalence of common mental disorders: a systematic review and meta-analysis 1980-2013. Int J Epidemiol. 2014;43(2):476-493.

10. Boeschoten RE, Braamse AM, Beekman AT, et al. Prevalence of depression and anxiety in multiple sclerosis: a systematic review and meta-analysis. J Neurol Sci. 2017;372:331-341.

11. Korostil M, Feinstein A. Anxiety disorders and their clinical correlates in multiple sclerosis patients. Mult Scler J. 2007;13(1):67-72.

12. Sá MJ. Psychological aspects of multiple sclerosis. Clin Neurol Neurosurg. 2008;110(9):868-877. 
13. Garfield AC, Lincoln NB. Factors affecting anxiety in multiple sclerosis. Disabil Rehabil. 2012;34(24):2047-2052.

14. Giordano A, Granella F, Lugaresi A, et al. Anxiety and depression in multiple sclerosis patients around diagnosis. J Neurol Sci. 2011;307(1-2):86-91.

15. Brown RF, Valpiani EM, Tennant CC, et al. Longitudinal assessment of anxiety, depression, and fatigue in people with multiple sclerosis. Psychol Psychother. 2009;82(1):41-56.

16. Hartoonian N, Terrill AL, Beier ML, Turner AP, Day MA, Alschuler KN. Predictors of anxiety in multiple sclerosis. Rehabil Psychol. 2015;60(1):91.

17. Henderson $A S$, Jorm AF, Korten $A E$, Jacomb $P$, Christensen $H$, Rodgers B. Symptoms of depression and anxiety during adult life: evidence for a decline in prevalence with age. Psychol Med. 1998;28(6):1321-1328.

18. Tan-Kristanto S, Kiropoulos LA. Resilience, self-efficacy, coping styles and depressive and anxiety symptoms in those newly diagnosed with multiple sclerosis. Psychol Health Med. 2015;20(6):635-645.

19. Jones $\mathrm{KH}$, Ford DV, Jones PA, et al. A large-scale study of anxiety and depression in people with multiple sclerosis: a survey via the web portal of the UK MS Register. PLoS ONE. 2012;7(7):e41910.

20. Beiske AG, Svensson E, Sandanger I, et al. Depression and anxiety amongst multiple sclerosis patients. Eur J Neurol. 2008;15(3):239-245.

21. Julian LJ, Arnett PA. Relationships among anxiety, depression, and executive functioning in multiple sclerosis. Clin Neuropsychol. 2009;23(5):794-804.

22. Morrow SA, Rosehart H, Pantazopoulos K. Anxiety and depressive symptoms are associated with worse performance on objective cognitive tests in MS. J Neuropsychiatry Clin Neurosci. 2015;28(2):118-123.

23. Bruce JM, Arnett P. Clinical correlates of generalized worry in multiple sclerosis. J Clin Exp Neuropsychol. 2009;31(6):698-705.

24. Grech LB, Kiropoulos LA, Kirby KM, Butler E, Paine M, Hester R. The effect of executive function on stress, depression, anxiety, and quality of life in multiple sclerosis. J Clin Exp Neuropsychol. 2015;37(5):549-562.

25. Akbar N, Honarmand K, Feinstein A. Self-assessment of cognition in multiple sclerosis: the role of personality and anxiety. Cogn Behav Neurol. 2011;24(3):115-121.

26. McDonald WI, Compston A, Edan G, et al. Recommended diagnostic criteria for multiple sclerosis: guidelines from the International Panel on the diagnosis of multiple sclerosis. Ann Neurol. 2001;50(1):121-127.

27. Kurtzke JF. Rating neurologic impairment in multiple sclerosis: an expanded disability status scale (EDSS). Neurology. 1983;33(11):1444.

28. Zigmond AS, Snaith RP. The hospital anxiety and depression scale. Acta Psychiatr Scand. 1983;67(6):361-370.

29. Honarmand K, Feinstein A. Validation of the Hospital Anxiety and Depression Scale for use with multiple sclerosis patients. Mult Scler J. 2009;15(12):1518-1524.

30. Krupp LB, LaRocca NG, Muir-Nash J, Steinberg AD. The fatigue severity scale: application to patients with multiple sclerosis and systemic lupus erythematosus. Arch Neurol. 1989;46(10):1121-1123.

31. Kaynak H, Altintaş A, Kaynak D, et al. Fatigue and sleep disturbance in multiple sclerosis. Eur J Neurol. 2006;13(12):1333-1339.

32. Amtmann D, Bamer AM, Noonan V, Lang N, Kim J, Cook KF. Comparison of the psychometric properties of two fatigue scales in multiple sclerosis. Rehab Psychol. 2012;57(2):159.

33. Broadbent DE, Cooper PF, FitzGerald P, Parkes KR. The cognitive failures questionnaire (CFQ) and its correlates. Br J Clin Psychol. 1982;21(1):1-6.

34. Ponds RW, Van Boxtel M, Jolles J. De Cognitive Failure Questionnaire als maat voor subjectief cognitief functioneren. Tijdschr Neuropsychologie. 2006;2:37-45.
35. Bol Y, Duits AA, Hupperts RM, Verlinden I, Verhey FR. The impact of fatigue on cognitive functioning in patients with multiple sclerosis. Clin Rehabil. 2010;24(9):854-862.

36. CBO. Richtlijn Multipele Sclerose (2012). Houten: Bohn Stafleu van Loghum.

37. Benedict RH, Fischer JS, Archibald CJ, et al. Minimal neuropsychological assessment of MS patients: a consensus approach. Clin Neuropsychol. 2002;16(3):381-397.

38. Van der Elst W, Van Boxtel MP, Van Breukelen GJ, Jolles J. The concept shifting test: adult normative data. Psychol Assess. 2006;18(4):424.

39. Luria AR. An Introduction to Neuropsychology. The Working Brain. Harmondsworth, UK: Penguin Books; 1973.

40. Luteijn F, Van der Ploeg FA. Handleiding Groninger Intelligentietest (git)[Manual Groningen Intelligence Test]. Lisse, the Netherlands: Swetz and Zeitlinger; 1983.

41. Schmand B, Groenink SC. Letter fluency: psychometric properties and Dutch normative data. Tijdschr Gerontol Geriatr. 2008;39(2):64-76.

42. Mulder JL, Dekker R, Deker PH. Verbale leer en Geheugen Test: Handleiding (VLGT)(Dutch Version of California Verbal Learning Test). Lisse, the Netherlands: Swets Test Services (STS); 1996.

43. Wechsler D. Wechsler Memory Test Administration and Scoring Manual. San Antonio, TX: The Psychological Corporation; 1997.

44. Watson D, Clark LA, Carey G. Positive and negative affectivity and their relation to anxiety and depressive disorders. J Abnorm Psychol. 1988;97(3):346.

45. Watson D, Clark LA. Negative affectivity: the disposition to experience aversive emotional states. Psychol Bull. 1984;96(3):465.

46. Hermelink $\mathrm{K}$, Küchenhoff $\mathrm{H}$, Untch $\mathrm{M}$, et al. Two different sides of 'chemobrain': determinants and nondeterminants of self-perceived cognitive dysfunction in a prospective, randomized, multicenter study. Psychooncology. 2010;19(12):1321-1328.

47. Dowlati $\mathrm{Y}$, Herrmann N, Swardfager W, et al. A meta-analysis of cytokines in major depression. Biol Psychiatry. 2010;67(5):446-457.

48. Beier M, Amtmann D, Ehde DM. Beyond depression: Predictors of self-reported cognitive function in adults living with MS. Rehabil Psychol. 2015;60(3):254.

49. Brands I, Bol Y, Stapert S, Köhler S, van Heugten C. Is the effect of coping styles disease specific? Relationships with emotional distress and quality of life in acquired brain injury and multiple sclerosis. Clin Rehabil. 2018;32(1):116-126.

50. Gascoyne CR, Simpson S Jr, Chen J, van der Mei I, Marck CH. Modifiable factors associated with depression and anxiety in multiple sclerosis. Acta Neurol Scand. 2019;140(3):204-211.

51. Ghielen I, Rutten S, Boeschoten RE, et al. The effects of cognitive behavioral and mindfulness-based therapies on psychological distress in patients with multiple sclerosis, Parkinson's disease and Huntington's disease: two meta-analyses. J Psychosom Res. 2019;122:43-51.

52. Heeren A, Maurage P, Philippot P. Revisiting attentional processing of non-emotional cues in social anxiety: a specific impairment for the orienting network of attention. Psychiatry Res. 2015;228(1):136-142.

\section{SUPPORTING INFORMATION}

Additional supporting information may be found online in the Supporting Information section.

How to cite this article: Wallis O, Bol Y, Köhler S, van Heugten C. Anxiety in multiple sclerosis is related to depressive symptoms and cognitive complaints. Acta Neurol Scand. 2020;141:212-218. https://doi.org/10.1111/ane.13191 